\title{
The Effects of Short-Term Emotional Intelligence Training on Preschool Teachers in Poland
}

\author{
Marzena Martyniak \\ Institute for Emotional Development, Warsaw, Poland \\ John Pellitteri \\ Queens College, City University of New York, New York, USA
}

\begin{abstract}
The development of emotional intelligence (EI) in preschool teachers is important because of the influence on classroom environment, student engagement and child development. This cluster sample experimental study included teachers (all female) in public and private nursey and preschools in Warsaw, Poland. The treatment group $(N=60)$ interventions included three monthly workshop training in EI that was supported by daily exercises for four weeks following the training in contrast to the control group $(N=44)$ that did not receive any intervention. Pretest-posttest comparisons as measured by the Polish Mayer-Salovey-Caruso Emotional Intelligence Test (MSCEIT) indicated treatment group increases in three of the four EI abilities (facilitation, knowledge and regulation) as well as the MSCEIT Strategic area. In posttest comparisons the treatment group was significantly higher than controls on the facilitation and regulation abilities and the strategic area. Results suggest that targeted interventions for teachers can improve EI abilities with short term training and hold promise for improved teacher development.
\end{abstract}

Keywords: emotional intelligence, preschool teachers, MSCEIT, intervention

\section{Introduction}

The importance of emotional intelligence (EI) and social-emotional learning (SEL) in education and child development has been well established (Brackett \& Katulak, 2006; Frey, Bobbitt Nolen, van Schoiack Edstrom, \& Hirschstein, 2005; Salovey \& Sluyter, 1997). Social-emotional capacities are relevant for mental health and as protective factors in coping and resilience for children (Cohen \& Kauffman, 2005; Goldstein \& Brooks, 2013) particularly for young (preschool age) children (Lynch, Geller, \& Schmidt, 2004). EI and SEL curricula have also been found to

John Pellitteri, Queens College-City University of New York, 65-30 Kissena Blvd Flushing, New York 11367, USA. E-mail: John.Pellitteri@qc.cuny.edu 
impact academic learning. In a meta-analytic study involving 213 school-based SEL programs, Durlak, Weissberg, Dymnicki, Taylor, and Schellinger (2011) found that SEL programs led to an $11 \%$ increase in academic performance.

Despite these findings, there are varying degrees to which EI has been embraced in educational curricula at different grade levels. The extension of EI curricula from elementary grades to younger children in pre-school and nursery schools is developing (Gershon \& Pellitteri, 2018; Rivers, Tominey, O’ Bryon, \& Brackett, 2013; Ulutas \& Omeroglu, 2007) but continued research at the preschool grade level is necessary. In addition, there are differences between various countries in the degree to which EI is recognized and embedded in education as well as the larger society.

An important factor in the delivery of EI and related interventions in schools is the role of the teacher. Not only are teachers usually responsible for delivering EI curriculum to students but they also model EI behaviours and create classroom environments that are conducive to students' academic learning and emotional development. A notable finding from the Durlak et al. (2011) meta-analysis found that caring support from teachers in their relationships with students was significant. McCormick, Cappella, O'Connor, and McClowry (2015) identified emotional support and classroom organization as factors contributing to academic achievement.

Bracket and colleagues (Brackett, Reyes, Rivers, Elbertson, \& Salovey, 2011; Reyes, Brackett, Rivers, White, \& Salovey, 2012) examined EI curricula in schools and the reciprocal relationships between classroom emotional climate with student conduct and academic grades. They found that these relationships were mediated by teacher affiliation and student engagement respectively. Hagelskamp, Brackett, Rivers, and Salovey (2013) found that treatment group classes using the RULER curriculum over a 2-year period improved classroom emotional support as well as organizational and instructional support over control conditions. These findings illustrate the important role of teachers and the classroom environment in the creation and maintenance of the emotional climate. As the key facilitators in the classroom, teachers' impact on the environment comes through emotion-based interactions. This, in turn, highlights the importance of developing EI in teachers.

EI interventions directed toward students and classroom improvement not only include the teacher as a facilitator but can also facilitate teachers' EI development. Castillo, Fernández-Berrocal, and Brackett (2013) in a study in Spain examined variables such as burnout for teachers in a treatment condition using the RULER curriculum versus a control (E-Learning) condition. They found significant gains on several variables for teachers in the treatment group, suggesting that EI curricula have implications for improving the quality of teaching practices and professional development. The importance of EI training for teachers has been established (Dolev \& Leshem, 2016; Palomera, Fernandez-Berrocal, \& Brackett, 2008).

The current study builds upon these findings of teacher training and examines the effectiveness of a 3-month EI intervention for preschool teachers. The 
intervention was based on the abilities model of EI (Mayer \& Salovey, 1997). The study is part of a larger project of developing EI in the educational system in Poland. The purpose is to contribute to the literature on EI in Polish education and extend EI applications to the preschool level.

\section{Method}

\section{Participants}

Participants were nursery and preschool teachers from 18 schools in Warsaw. All participants were female with age ranges between 25 and $55\left(M_{\text {age }}=32.5\right)$. The total participants after attrition were 104 (60 in treatment group and 44 in control conditions). The initial number of participants in the groups was larger (66 treatment group and 61 control group), however, several participants did not complete the posttest because they were no longer employed at the schools or chose to withdraw from the study. Other participants did complete both pre and posttest measures, however, their responses were incomplete so their MSCEIT results could not be adequately scored. Only participants with completed measures at both times of assessment were retained in the study. One possible difference for the lower attrition rate in the treatment group (9\%) versus the control group (27\%) is that the former was engaged through the treatment intervention and was presumably more invested in the study, whereas the latter did not have an on-going contact with the researcher over the three months.

\section{Instruments}

Mayer-Salovey-Caruso Emotional Intelligence Test (MSCEIT) is an abilitybased performance measure that yields four hierarchical levels of scores (Mayer, Salovey, \& Caruso, 2002). At the first and lowest level of the test structure are eight separate tasks that require the participant to perform an EI ability such as identify faces in pictures or answer questions about emotion concepts or emotional skills. The next level includes the four ability scores (branches) that are each comprised of two task scores. The four abilities are (1) perception, which requires the accurate identification of emotions in faces and visual scenes, (2) facilitation, which includes sensory access to feelings and emotional planning in social situations, (3) knowledge, which comprises a conceptual understanding of complex emotions and transitions, and (4) regulation, which includes the abilities to manage emotional states in oneself and in others. The third level of the MSCEIT structure is the area scores. The first two abilities (perception and facilitation) form the Experiential Area that refers most predominantly to processing the intake of emotional information. The third and fourth abilities (knowledge and regulation) comprise the Strategic Area score which represents adaptive actions based on emotions. The total score at the fourth and highest level is derived from the two area scores. 
The scoring method for the study was consensus scoring based on the means of the test's norm groups. Reliability and validity for the MSCEIT were established through factorial, predictive and discriminant comparisons in numerous studies as described by Mayer et al. (2002).

Demographic Questionnaire obtained basic information on participants. Additional measures were administered as part of a larger study but only the preliminary findings on the main effect are available and are analysed and reported here.

\section{Procedure}

Participants were assigned to treatment or control conditions by a cluster sampling of schools. Teachers in the treatment conditions attended the workshops in a central location. The treatment group intervention included three monthly full-day EI training workshops with short daily follow-up exercises (five times per week) that were administered through e-mails for four weeks following the training. Control group participants did not receive any interventions.

\section{Results}

Analyses included independent sample $t$-tests for pretests and posttests analyses and paired sample $t$-tests for pre-post analyses of treatment and control groups.

Table 1 reports the descriptive statistics of the dependent variable for the treatment and control groups. The group comparisons were conducted at the level of MSCEIT abilities, areas and total scores. The independent $t$-test comparisons for the pretests as reported in Table 2 indicate that there were no significant differences between treatment and control groups on any of the EI abilities measure (MSCEIT) variables. This suggests that there were equivalent levels of EI abilities before treatment intervention.

Table 1

Descriptive Statistics of Mayer-Salovey-Caruso Emotional Intelligence Test (MSCEIT)

\begin{tabular}{llrrr}
\hline & $N$ & $M$ & \multicolumn{1}{c}{$S D$} & \multicolumn{1}{c}{$V$} \\
\hline Treatment Group & & & & \\
\hline Perception Ability & 59 & 93.07 & 15.51 & 240.71 \\
Facilitation Ability & 59 & 92.45 & 11.91 & 141.92 \\
Knowledge Ability & 60 & 87.27 & 8.64 & 74.82 \\
Management Ability & 59 & 85.42 & 8.73 & 76.21 \\
\hline Experiential Area & 58 & 91.30 & 13.25 & 175.65 \\
Strategic Area & 59 & 85.77 & 6.98 & 48.85 \\
\hline MSCEIT Total & 57 & 86.42 & 9.46 & 89.49 \\
\hline
\end{tabular}


Martyniak, M., Pellitteri, J.:

Emotional Intelligence in Preschool Teachers

\begin{tabular}{lllll}
\hline & $N$ & $M$ & $S D$ & $V$ \\
\hline Control Group & & & & \\
\hline Perception Ability & 43 & 96.33 & 15.67 & 245.68 \\
Facilitation Ability & 43 & 89.91 & 12.87 & 165.88 \\
Knowledge Ability & 44 & 88.89 & 11.94 & 142.63 \\
Management Ability & 42 & 83.25 & 11.64 & 135.54 \\
\hline Experiential Area & 43 & 92.45 & 14.47 & 209.45 \\
Strategic Area & 42 & 84.84 & 11.86 & 140.81 \\
\hline MSCEIT Total & 41 & 85.41 & 11.56 & 133.75 \\
\hline
\end{tabular}

Table 2

Independent Samples T-Test for Treatment and Control Group MSCEIT Pretests

\begin{tabular}{lrcccc}
\hline & $t$-test & $d f$ & $p$ & Mean Difference & S.E. Difference \\
\hline Perception Ability & -1.04 & 100 & .299 & -3.26 & 3.12 \\
Facilitation Ability & 1.02 & 100 & .306 & 2.54 & 2.47 \\
Knowledge Ability & -0.76 & 74.12 & .446 & -1.62 & 2.11 \\
Regulation Ability & 1.02 & 72.21 & .312 & 2.16 & 2.12 \\
\hline Experiential Area & -0.41 & 99 & .69 & -1.14 & 2.77 \\
Strategic Area & 0.45 & 61.11 & .64 & 0.93 & 2.04 \\
\hline MSCEIT Total & 0.47 & 96 & .63 & 1.01 & 2.12 \\
\hline
\end{tabular}

The control group pretest - posttest paired sample $t$-test comparisons (See Table 3 ) indicate that no significant within-group difference occurred during the course of the study.

Table 3

Paired Samples T-Test for Control Group MSCEIT Pretest - Posttests

\begin{tabular}{|c|c|c|c|c|c|c|}
\hline & $M$ & $S D$ & S.E. & $t$-test & $d f$ & $p$ \\
\hline Pair 1 Perception O1-O2 & .79 & 18.15 & 2.76 & 0.28 & 42 & .777 \\
\hline Pair 2 Facilitation $\mathrm{O} 1-\mathrm{O} 2$ & -.47 & 11.82 & 1.80 & -0.26 & 42 & .794 \\
\hline Pair 3 Knowledge O1-O2 & .36 & 7.10 & 1.07 & 0.34 & 43 & .734 \\
\hline Pair 4 Regulation $\mathrm{O} 1-\mathrm{O} 2$ & -.41 & 4.41 & 0.68 & -0.60 & 41 & .550 \\
\hline Pair 5 Experiential O1-O2 & .68 & 16.32 & 2.48 & 0.27 & 42 & .783 \\
\hline Pair 6 Strategic O1-O2 & .11 & 5.97 & 0.92 & 0.12 & 41 & .901 \\
\hline Pair 7 MSCEIT Total O1-O2 & .18 & 9.39 & 1.46 & 0.12 & 40 & .901 \\
\hline
\end{tabular}

Note. $\mathrm{O} 1=$ Observation 1 (pretest); $\mathrm{O} 2=$ Observation 2 (posttest); S.E. = standard error mean.

Table 4 illustrates the treatment group pretest - posttest comparisons. The treatment intervention is associated with significant increases in three of the four MSCEIT branches (facilitation, knowledge, regulation) as well as one area score (Strategic). 
Table 4

Paired Sample T-Tests for Treatment Group MSCEIT Pretest - Posttest

\begin{tabular}{|c|c|c|c|c|c|c|}
\hline & $M$ & $S D$ & S.E. & $t$-test & $d f$ & $p$ \\
\hline Pair 1 Perception O1-O2 & 2.89 & 17.85 & 2.34 & 1.23 & 57 & .222 \\
\hline Pair 2 Facilitation $\mathrm{O} 1-\mathrm{O} 2$ & -4.54 & 14.57 & 1.91 & -2.37 & 57 & $.021^{*}$ \\
\hline Pair 3 Knowledge O1-O2 & -4.05 & 10.15 & 1.31 & -3.08 & 59 & $.003^{* *}$ \\
\hline Pair 4 Regulation $\mathrm{O} 1-\mathrm{O} 2$ & -3.88 & 10.86 & 1.42 & -2.72 & 57 & $.009^{* *}$ \\
\hline Pair 5 Experiential O1-O2 & -.61 & 14.74 & 1.97 & -.31 & 55 & .757 \\
\hline Pair 6 Strategic O1-O2 & -4.00 & 8.28 & 1.08 & -3.68 & 57 & $.001^{* *}$ \\
\hline Pair 7 MSCEIT Total O1-O2 & -2.47 & 9.90 & 1.34 & -1.83 & 53 & .072 \\
\hline
\end{tabular}

Note. $\mathrm{O} 1=$ Observation 1 (pretest); $\mathrm{O} 2=$ Observation 2 (posttest); S.E. $=$ standard error mean; ${ }^{*} p<.05$; ${ }^{* *} p<.01$.

Three of the four significant variables that increased in the treatment intervention were significant compared to the control group. Two abilities (facilitation and regulation), as well as one areas score (Strategic), were significantly higher, as reported in Table 5.

Table 5

Independent Samples T-Tests for Treatment and Control Group MSCEIT Posttests

\begin{tabular}{lcrlcc}
\hline & $t$-test & $d f$ & $p$ & Mean Difference & S.E. Difference \\
\hline Perception Ability & -1.56 & 101 & .121 & -4.25 & 2.72 \\
Facilitation Ability & 2.50 & 100 & $.014^{*}$ & 6.61 & 2.64 \\
Knowledge Ability & 1.25 & 102 & .211 & 2.79 & 2.22 \\
Regulation Ability & 2.35 & 100 & $.020^{*}$ & 5.33 & 2.26 \\
\hline Experiential Area & 0.15 & 99 & .874 & 0.36 & 2.32 \\
Strategic Area & 2.54 & 100 & $.012^{*}$ & 5.08 & 1.99 \\
\hline MSCEIT Total & 1.87 & 97 & .065 & 3.99 & 2.13 \\
\hline
\end{tabular}

Note. ${ }^{*} p<.05 ;{ }^{* *} p<.01$.

\section{Discussion}

The results indicate that the 3-month EI training intervention for teachers was effective at increasing three of the four MSCEIT ability areas (facilitation, knowledge and regulation). The facilitation ability involves emotional planning (i.e. anticipating how someone might feel or matching what emotion would be most productive in a given situation) which is a relevant capacity for teacher classroom interventions. The emotional knowledge ability involves the conceptual understanding of emotions (such as the causes of feelings) which can be more readily taught in workshop settings. While the knowledge ability increased in the treatment group posttest measure it was not significantly higher than the control group posttest 
suggesting that without intervention, some degree of emotion knowledge increased. Lastly, the regulation ability may be most relevant to classroom teaching in the form of managing students' emotions as well as teachers managing their own emotions during the day.

At the level of MSCEIT area scores, the Strategic Area significantly increased as a result of the intervention. This variable is derived from the knowledge and regulation abilities and therefore reflects the increases in both of those components. The strategic area overall may also reflect the extent of the teachers' interests in practical applications of classroom management. The relevance of such strategic area abilities for classroom management may have led teachers to be more focused on these abilities.

The perception ability did not increase in the treatment condition even though the workshops and follow up exercises were aimed at all four of the Mayer and Salovey (1997) abilities. One reason could be that EI perception appears to be more distinct from the other MSCEIT abilities as suggested in factor analytic examinations (Pellitteri \& Lei, 2016). EI perception may be based more in temperament and rely more strongly on neurological processing than the other abilities which tend to involve greater cognitive processing (and thus be more sensitive to workshop training). Another reason could be that the experiential practice of EI perception abilities in preschool classes is minimal given the young children's limited range of expressed feelings and simple basic emotions (Lewis, 2016). Teachers may not have been challenged at recognizing affective cues beyond the primary emotions that are already within an adult repertoire.

The increase in EI abilities as a result of a short term (3-month) intervention is promising in that educational systems could impact teacher development without extensive resources or training. An identified need is to increase the salience of EI in education in Poland and such a cost-effective method could be important for this purpose. However, long term studies (e.g., Hagelskamp et al., 2013; Lynch et al., 2004) suggest that sustained EI interventions with students will have a significant impact and other studies (e.g., Brackett et al., 2011) identify teachers as one of several facilitating factors. While short term interventions may be desirable for school administrators with limited budgets and limited time for teacher development, long term teacher development interventions must be considered because of the promise of sustainability.

One limitation in this current study is the examination of preliminary data without long term follow up. It is therefore not known how long these increases in EI will last. This need will be addressed by a 2-year study that is currently in progress as part of the larger project by the Institute for Emotional Development in Poland. Another limitation of the current study is the potential carry-over effect on the posttest measurement after only a few months. There is little evidence from the literature to examine the sensitivity of this effect with the MSCEIT, however, the non-significant changes in the control group posttest suggest that this is not a 
confounding factor. This measurement issue will also be addressed in the 2-year study that conducts posttest assessment on a yearly basis. Lastly, the on-going 2-year studies will include multiple assessments of personality and class environment that will balance the limitations of this current study that only examined the dependent variable.

One direction for future research will be to examine the effects of teacher EI on students. While the short-term intervention was effective in increasing EI abilities, it is not yet known how teachers' abilities translate to student gains in Poland. Such influences will need to be examined in the context of classroom- and school-wide EI interventions that directly teach EI skills to students and that consider factors in the classroom environment. The on-going 2-year study aims to explore this effect.

Another area for future research is in the delivery of EI teacher training. The intervention had two major components, the three full-day workshops and the daily follow up. The former is a common format for most teacher training programs. However, it is believed that many of the gains in teacher EI abilities may have been sustained by the continued daily reminders and exercises that the teachers did over the four weeks following the training. Future research could involve a component analysis that compares this study's intervention with a workshop only group to ascertain the impact of the daily exercises. Teacher and student development can be parallel in that both involve learning processes, so sustained daily interventions will likely improve teachers' EI the way it impacts students' emotional learning.

\section{References}

Brackett, M. A., \& Katulak, N. A. (2006). Emotional intelligence in the classroom: A skillbased training for teachers and students. In J. Ciarrochi \& J. D. Mayer (Eds.), Improving emotional intelligence: A practitioner's guide (pp. 1-27). New York: Psychology Press.

Brackett, M. A., Reyes, M. R., Rivers, S. E., Elbertson, N. A., \& Salovey, P. (2011). Classroom emotional climate, teacher affiliation, and student conduct. Journal of Classroom Interaction, 46(1), 27-36. http://www.jstor.org/stable/23870549

Castillo, R., Fernández-Berrocal, P., \& Brackett, M. A. (2013). Enhancing teacher effectiveness in Spain: A pilot study of the RULER approach to social and emotional learning. Journal of Education and Training Studies, 1(2), 263-272. doi:10.11114/ jets.v1i2.203

Cohen, E., \& Kaufmann, R. (Eds). (2005). Early childhood mental health consultation. Nashville: Vanderbilt University, the Center on the Social and Emotional Foundations for Early Learning.

Dolev, N., \& Leshem, S. (2016). Teachers' emotional intelligence: The impact of training. International Journal of Emotional Education, 8(1), 75-94. 
Durlak, J. A., Weissberg, R. P., Dymnicki, A. B., Taylor, R. D., \& Schellinger, K. B. (2011). The impact of enhancing students' social and emotional learning: A meta-analysis of school-based universal interventions. Child Development, 82(1), 405-432.

Frey, K. S., Bobbitt Nolen, S., van Schoiack Edstrom, L., \& Hirschstein, M. K. (2005). Effects of a school-based social-emotional competence program: Linking children's goals, attributions and behavior. Applied Developmental Psychology, 26, 171-200.

Gershon, P., \& Pellitteri, J. S. (2018) Promoting emotional intelligence in preschool education: A review of programs. International Journal of Emotional Education, 10(2), 26-41.

Goldstein, S., \& Brooks, R. B. (Eds.) (2013). Handbook of resilience in children (2 ${ }^{\text {nd }}$ ed). New York: Springer.

Hagelskamp, C., Brackett, M. A., Rivers, S. E., \& Salovey, P. (2013). Improving classroom quality with the RULER approach to social and emotional learning: Proximal and distal outcomes. American Journal of Community Psychology, 51, 530-543. doi:10.1007/ s10464-013-9570-On-line

Lewis, M. (2016). The emergence of human emotions. In L. Feldman Barrett, M. Lewis, \& J. M. Haviland-Jones (Eds.), Handbook of emotions, $4^{\text {th }}$ ed. (pp. 272-292). New York: Guilford.

Lynch, K. B., Geller, R. S., \& Schmidt, M. G. (2004). Multi-year evaluation of the effectiveness of a resilience-based prevention program for young children. The Journal of Primary Prevention, 24(3), 335-353.

Mayer, J. D., \& Salovey, P. (1997). What is emotional intelligence? In P. Salovey \& D. J. Sluyter (Eds.), Emotional development and emotional intelligence (pp. 3-31). New York, N.Y.: Harper Collins.

Mayer, J. D., Salovey, P., \& Caruso, D. (2002). Mayer-Salovey-Caruso Emotional Intelligence Test. Toronto, Canada: Multi-Health Systems.

McCormick, M. P., Cappella, E., O’Connor, E. E., \& McClowry, S. G. (2015). Socialemotional learning and academic achievement: Using causal methods to explore classroom-level mechanisms. AERA Open, 1(3), 1-26. doi:10.1177/ 2332858415603959

Palomera, R., Fernandez-Berrocal, P., \& Brackett, M. A. (2008). Emotional intelligence as a basic competency in pre-service teacher training: Some evidence. Electronic Journal of Research in Educational Psychology, 6(2), 437-454.

Pellitteri, J. S., \& Lei, N. (2016). Which emotional intelligence: A comparison of measures and implications for counseling psychology. Psychology Research, 6(2), 57-68.

Reyes, M. R., Brackett, M. A., Rivers, S. E., White, M., \& Salovey, P. (2012). Classroom emotional climate, student engagement, and academic achievement. Journal of Educational Psychology, 104(3), 700-712. doi:10.1037/a0027268 
Rivers, S. E., Tominey, S., O’ Bryon, E., \& Brackett, M. (2013). Developing emotional skills in early childhood settings using preschool RULER. Psychological Education Review, $37,20-25$.

Salovey, P., \& Sluyter, D. J. (1997). Emotional development and emotional intelligence. New York: Harper Collins.

Ulutas, I., \& Omeroglu, E. (2007). The effects of an emotional intelligence education program on the emotional intelligence of children. Social Behavior and Personality, 35(10), 1365-1372.

Received: December 1, 2019 